\title{
Square Shape
}

National Cancer Institute

\section{Source}

National Cancer Institute. Square Shape. NCI Thesaurus. Code C48350.

A plane rectangle with four equal sides and four right angles; a four-sided regular

polygon. 